\title{
CONTENTS
}

Preface xi

Introduction

Barbara Bird, Doug Downs, I. Moriah McCracken, and Jan Rieman 3

1. Writing about Writing: A History

Barbara Bird, Doug Downs, I. Moriah McCracken, and Jan Rieman 13

\section{PART I: WRITERLY IDENTITIES}

2. Threshold Concepts as a Foundation for "Writing about Writing" Pedagogies

Elizabeth Wardle and Linda Adler-Kassner 23

3. Writing about Writing in the Disciplines in First-Year Composition Rebecca Robinson 35

4. Student Volce: Reflections on Our Freshman Writing Course Emma Gaier and Megan Wallace 47

5. (Dis)Positioning Writing Confidence, Reflecting on Writer Identity: A Writing about Writing Curriculum Aimed at Knowledge Transfer Lisa Tremain 56

6. Student Voice: Writing about Writing: Leading to New Perspectives

Hiroki Sugimoto 68

7. Vignette: WAW-Professional Writing for STEM Co-op Students Joy Arbor 71

8. "I Am Seen; I Am My Culture; and I Can Write": How WAW Returns Multilingual Learners to Voice, Building Self-Efficacy and Rhetorical Flexibility 
9. Vignette: El Ensayo: Latinxs Writing about Writing Nancy Wilson, Rebecca Jackson, and Valerie Vera 88

10. Vignette: "Writing Is Like Shaping a Bonsai Tree": Writing about Writing and Culture in a Developmental Composition Course Gwen Hart 97

11. Why I Keep Teaching Writing about Writing in Qatar: Expanding Literacies, Developing Metacognition, and Learning for Transfer Mysti Rudd 101

12. Next Steps, or Rather, One Step at a Time: A How-To Guide for Implementing Writing about Writing

Kristen di Gennaro 112

13. Developing a Writing about Writing Curriculum

Cat Mahaffey and Jan Rieman

123

\section{PART II: PROCESS}

14. Vignette: Community College Composition, Critical Literacy, and the Writing about Writing Curriculum

Shawn Casey 137

15. Vignette: FYC Students as Writing Studies Scholars: Promoting Procedural Knowledge through Participation

Andrew Ogilvie 143

16. Vignette: Processes of Engagement: A Community College Perspective

Olga Aksakalova and Dominique Zino 146

17. Vignette: Engineering Writing about Writing in Engineering: Experiments in Technical Writing and Collaborative Design

Andrew Lucchesi $\quad 150$

18. Vignette: Writing about Writing Pedagogy in a Mixed Major/ Nonmajor Professional Writing Course

Gabriel Cutrufello 155

19. Negotiating WAW-PW across Diverse Institutional Contexts Sarah Read and Michael J. Michaud 159 
20. Vignette: A Unique Pair: Pairing WAW in a First-Year Writing Sequence as the First Step in Academic Research

Frances Johnson

172

21. Vignette: Researching about Research, Writing about Writing from Sources

Elizabeth Kleinfeld

177

22. Vignette: The FYW WAW Composition Classroom Reimagined: Threshold Concepts through Gamification

Samuel Stinson 180

23. Curricular Review in WAW: Involving Alumni, Students, and Faculty in Writing about Writing in Technical Fields

Jennifer deWinter 187

\section{PART III: ENGAGEMENT}

24. Transfer of Writing-Related Learning

Rebecca S. Nowacek 201

25. Student Voice: Writing about Writing Focus: A Roundtable

Kimberly Hoover with Elle Limesand, Maggie Hammond, and Max Wellman 209

26. Finding a Way into WAW: Extending Invitations across Disciplinary Lines

Matthew Bryan, Kevin Roozen, and Nichole Stack 220

27. Digital Composing in WAW: What Students Learn through Infographics

Christy I. Wenger 234

28. Student Voice: Podcasting and Protocols: An Approach to Writing about Writing through Sound

Christian Smith with Gabrielle Frick and Patrick Siebel

252

29. Play the Game but Refocus the Aim: Teaching WAW within Alternative Pedagogies

Katie Jo LaRiviere $\quad 261$ 
Conclusion: Afterwards and Forwards

Barbara Bird, Doug Downs, I. Moriah McCracken, and Jan Rieman

List of Contributors

281

Index

287 


\section{INTRODUCTION}

Barbara Bird, Doug Downs,

I. Moriah McCracken, and Jan Rieman

This book captures a representative variety of "writing about writing" (WAW) approaches to teaching writing that composition teachers are currently using. The authors of this book do not offer a singular set of practices or assignments or readings. We are deliberately calling WAW an approach, not a "pedagogy," since pedagogy may elicit thoughts of techniques or practices in a classroom. Similarly, we have chosen approach over "curriculum," since this term may leave readers asking for reading assignments and writing assignments. Though pedagogical techniques and the curricular design are here, our guiding purpose has been to help our readers, and us, see the breadth of current WAW approaches.

The approaches the field generally recognizes as "writing about writing" are founded on three principles for writing instruction, not a singular class or set of assignments (for example, ones mirroring those outlined by Doug Downs and Elizabeth Wardle in 2007). The first and foundational principle of the WAW approach is making writing itself the object of study in the writing classroom, regardless of course level. WAW courses study writing-in all its forms and with all its related concepts, including rhetoric, discourse, and literacy-as the content of the course, the subject of pieces students write. The content of WAW matters because it is in wrestling with writing concepts (both threshold and other key concepts) that students think deeply about what writing is, does, and means to them, and it is in writing about these concepts that students form their writer identities and develop deep writing knowledge. Writer identities and writing concept knowledge tends to result in an improved ability to discern what each new writing situation requires. In this way, WAW courses aren't interested in telling students how to write or what to write. Instead, they invite students into deep, meaningful conversations about writing and reflection on themselves as writers.

Part of the effectiveness of these writing concept conversations and writerly self-reflections stems from the second WAW principle: students 
are viewed as writers, not student writers. WAW acknowledges that no one is ever done learning to write, and by centering conversations around what scholars in writing know about writing-the research findings, terms and concepts, and effective practices-we explore what is still unknown with our students, who bring new experiences and practices into the classroom each semester. This is why WAW courses position students as novices, or individuals just beginning their study of writing as an artifact and studyable subject; and as novices, students are positioned in WAW courses as advancing along a continuum, not toward mastery but instead toward emerging expertise.

The third WAW principle is that WAW instructors want to advance writing knowledge with students. WAW asks students to be scholars with us; for ten or fifteen weeks, WAW instructors ask students to wrestle with ideas of what it means to be a reader, a writer, a literate citizen in the twenty-first century. What is most important in this reorientation toward students as novice scholars of writing knowledge is that WAW teachers want to discover this knowledge with students, not for them. WAW instructors, in other words, act precisely like the best faculty in general education courses across the rest of the curriculum: asking students for a moment to become practitioners of (rather than merely bodies acted upon by) a discipline that is not "theirs" but in which some fluency will be of great value to any educated individual. Using writing as the object of study and bringing students into the conversation with us about what we know about how writing works, focusing on how writing works for each student, is a key feature of WAW courses.

Instructors and students from a wide range of institutions composed the chapters and vignettes included here, and these voices and examples reveal how instructors and students collaborate to define more specifically what WAW means in local contexts. Because these contextualized settings play a large role in why and how each author developed his or her particular WAW approach, we preface chapters that discuss a specific classroom instantiation with a box listing a set of institutional context variables. In courses across the range of settings featured in this book, the three principles continually reemerge: writing is the content, students are writers, and instructors discover new knowledge with and not for student writers. A key result is that this use of declarative knowledge about writing to support students' identities as writers enables them to evidence understanding and choice in their own procedural approaches to writing.

Our initial call for contributions to this book was a very broad question: how are you using WAW? As we began to carefully listen to the 
descriptions of WAW submitted by our contributors, we eventually realized that the diverse WAW approaches might best be arranged by the three most common outcomes of these WAW practices: sharpened writerly identities, extended writing processes, and deeper writer engagement.

\section{PART I: WRITERLY IDENTITIES}

Treating students as writers, explicitly equipping them to develop their own writerly identities, requires us to process with them knowledge about writing, for all identities can only be developed after knowing something about that with which we want to identify. Though our students engage with multiple writerly communities just in their college courses alone, the most effective foundation for all of these communities is the sense of being a writer since it is writers who construct knowledge and ask questions. By treating students as writers, a WAW course helps students learn how to become agile and adaptive writers who know what questions to ask when moving into any writing situation and who feel confident in their abilities to figure out how to do the work required in each situation. We share writing knowledge resources with our students as those who have a bit more established writer identities, attempting to shift the culture of first-year writing toward a mentoring system: teachers and students talking about writing as writers, encouraging students to own their writer identities. This explicit invitation and equipping helps students move from doing writing to being a writer.

In this section, authors examine writerly identities from several perspectives, starting with a foundation for creating writerly identities: threshold concepts about writing. In "Threshold Concepts as a Foundation for 'Writing about Writing' Pedagogies," Elizabeth Wardle and Linda Adler-Kassner note that there are core principles and concepts that form the foundation of a WAW curriculum and upon which individual instructors can build when they construct courses about writing as a subject of study. Wardle and Adler-Kassner demonstrate how those principles and concepts are linked to our discipline's knowledge base-the "threshold concepts" of writing studies-and their work on threshold concepts is particularly important for this collection because research suggest that threshold concept knowledge results in a level of learning that "reflects identity-changing embodiment," which is best studied through multiple data points, such as those offered here.

Rebecca Robinson opens this discussion about research into WAW classrooms in her chapter, "Writing about Writing in the Disciplines in First-Year Composition," which uses a single WAW-focused assignment 
to help students retheorize writing as a way to understand key threshold concepts-not simply transmit information. This teacher-research discussion is followed by a student voice chapter, "Reflections on Our Freshman Writing Course," in which Emma Gaier and Megan Wallace, two dual-enrollment students, discuss how they each used writing concepts to join communities of practice by engaging in conversations, not reporting on their learning. In "(Dis)Positioning Writing Confidence, Reflecting on Writer Identity: A Writing about Writing Curriculum Aimed at Knowledge Transfer," Lisa Tremain draws connections between literate identity, self-efficacy, writing development, and transfer. Her classroom research suggests that self-efficacy and writer identity are inextricable from how writing transfer is successfully enacted-a claim in conversation with another student voice piece as well as a vignette. In "Writing about Writing: Leading to New Perspectives," Hiroki Sugimoto, a student enrolled in a WAW course, notes how particular class readings and his understanding of discourse communities helped him develop his own relationship to writing. In Joy Arbor's "WAW-Professional Writing for STEM Co-op Students" vignette, we learn how a WAW course helps students write about their process of writing and reflect on themselves as writers in order to facilitate selfteaching. That is, Arbor's students become more explicitly aware of themselves as professional writers, which helps them transform general principles to multiple situations.

The contributions in this writerly identities section also offer insight into how WAW courses can serve the complex needs of multilingual writers. In "'I Am Seen; I Am My Culture; and I Can Write': How WAW Returns Multilinguâl Learners to Voice, Building Self-Efficacy and Rhetorical Flexibility," Christina Grant suggests that a WAW course design helps multilingual students reestablish their voices and roles in academic writing, integrate the rhetorical traditions of their mother tongue, and make progress on becoming confident, multidimensioned, linguistically hybrid thinkers and writers. In their coauthored vignette, "El Ensayo: Latinx Writing about Writing," Nancy Wilson, Rebecca Jackson, and Valerie Vera demonstrate how a WAW approach with Latinx writers can help encourage students to become aware of the "interconnections between their academic identity and language experiences" and to use such interconnections as writing strategies for college writing expectations. In her vignette, "Writing Is Like Shaping a Bonsai Tree': Writing about Writing and Culture in a Developmental Composition Course," Gwen Hart keeps with the WAW principle that students are writers within a community of learners. Hart's WAW course 
develops students' understandings of writing and aspects of their home cultures by asking students to think about how they understand writing through comparison. By linking writing to another familiar activity, Hart creates opportunities for students to think about their writing processes in a nonthreatening way so that they can examine the strengths and weaknesses of their current approaches to writing.

Mysti Rudd's chapter, "Why I Keep Teaching Writing about Writing in Qatar: Expanding Literacies, Developing Metacognition, and Learning for Transfer," explores the use of WAW in classrooms abroad. Rudd guides her students through an exploration of their identities as writers and transfer-inspired reflections about the usefulness of the premises they previously held about academic writing and reading. The work on reflection and writerly identities is then picked up by Kristen di Gennaro's "Next Steps, or Rather, One Step at a Time: A How-To Guide for Implementing Writing about Writing." Using her class as an example, di Gennaro suggests that while WAW writing tasks might draw on students' observations and reflections, WAW, as envisioned by di Gennaro, is not simply "writing about my writing." This section of the book closes with another chapter dealing with the programmatic role of WAW. In "Developing a Writing about Writing Curriculum," Cat Mahaffey and Jan Rieman suggest that WPAs who aim to develop a WAW program start with teacher identity. Mahaffey and Rieman argue that it is the shift in teacher identity that WAW prompts that enables student identities to shift. Engaged instructors who "own" the curriculum focus on the identity of the instructors and what that identity requires of them.

\section{PART II: PROCESS}

Like most writing teachers, WAW instructors do not view process as a list of practices to be completed in a particular order, like a checklist. More specifically, though, process in WAW classrooms is tied to who students are as writers and as knowledge makers since writing processes do not entail simply generating a draft or product but, more important, are a way to get to knowledge. Though most writing instructors want process made visible to their students, for many writers it isn't visible, at least not in the traditional way of viewing "the writing process." Some writers think and even "write" multiple drafts before putting hands to a keyboard; some writers keyboard only to discover their thinking after their third or tenth draft. WAW, like many writing approaches, invites students to engage in their own unique processes; but unlike other writing approaches, WAW invites students to study writing processes: what 
do they do and why? What have other writers done and why? How does writing-thinking work and why? These kinds of metacognition engage our WAW writers in reflective, rhetorical decision making.

Chapters included in this section reveal how, in WAW classrooms, process is not only tied to who students are as writers but also functions in service of identity. This identity-focused writing process perspective results from WAW instructors inviting students to connect who they are to all aspects of their writing, including their writing process. WAW emphasizes helping student writers know how they got to their final draft and learn how to replicate whatever process is successful for them. Emphasizing the effective and even ineffective processes students bring into classrooms helps WAW teachers to make explicit their goal of inviting writers to adapt and adopt cognizant practices for greater rhetorical understanding and greater content learning in any writing situation in or beyond school.

This section opens with Shawn Casey's vignette, "Community College Composition, Critical Literacy, and the Writing about Writing Curriculum." Casey's WAW students develop a more sophisticated understanding of the expanding literacies in our world, and by recognizing and writing about how literacy is learned, or not learned, Casey's students begin to build a context for understanding why so much emphasis is placed on "processes" in their later courses. Andrew Ogilvie also sees his students as novice writers, and he invites them to use that position to explore disciplinary genres. In his vignette, "FYC Students as Writing Studies Scholars: Promoting Procedural Knowledge through Participation," Ogilvie explores how his WAW course helps students think about how they approach writing, aiming to move students recursively between knowing what and knowing how with an end goal of helping them learn how to write themselves into a discourse community by exploring writing as ecology. Olga Aksakalova and Dominique Zino also want to help their students think differently about their processes, but their course focuses more directly on dispelling the myth that good writers don't need a writing process. To do this, Aksakalova and Zino give students the tools for navigating problems in their own writing process, showing students that expert writers also struggle and helping students verbalize their own difficulties. Aksakalova and Zino end their vignette, "Processes of Engagement: A Community College Perspective," by noting how they offer students strategies to analyze themselves as writers.

The idea of students exploring discourse communities also appears in Andrew Lucchesi's vignette, "Engineering Writing about Writing in Engineering: Experiments in Technical Writing and Collaborative 
Design." In this WAW course, students read professional texts on writing as engineers, and they conduct primary research into their own writing processes. In teaching his students genre and discourse community concepts, Lucchesi helps his engineering students gain career writing knowledge that can be directly applied to themselves as novice engineers. Gabriel Cutrufello's vignette, "Writing about writing Pedagogy in a Mixed Major/Nonmajor Professional Writing Course," uses genres rather than discourse communities to introduce students to writing studies terminology, critical perspectives, and research activities. These elements help his students construct a meaningful understanding of writing, fostering a metacognitive awareness. Cutrufello's specific WAW content is business writing genres and activities- the context of his students' chosen fields and careers.

Sarah Read and Michael Michaud explore how WAW can work in discipline-focused settings in their full-length chapter, "Negotiating WAW-PW across Diverse Institutional Contexts." Read and Michaud begin with their belief that students learn disciplinary knowledge from scholarly articles about professional writing, which situates students as professional researchers, or what they refer to as knowledge transformers. They then discuss their process of helping students situate themselves in their professions. Frances Johnson is also asking students to view themselves as researchers, not just students. In her vignette, "A Unique Pair: Pairing Writing about Writing in a First-Year Writing Sequence as the First Step in Academic Research," Johnson discusses her major assignment, an auto-ethnography as a writer, which requires original research, analysis of peers as writers, and an analysis of scientific discourse. Johnson has found that this WAW approach helps students view themselves more explicitly as writers engaging in discourse community writing and genres. Elizabeth Kleinfeld picks up the conversation about research, arguing that it can help students understand the complexity of source use in her vignette, "Researching about Research, Writing about Writing from Sources.” Kleinfeld uses WAW to guide her students through a study of their own writing as an artifact, an approach that helps students understand source use through a consideration of their own past use of sources.

Samuel Stinson's vignette, "The FYW WAW Composition Classroom Reimagined: Threshold Concepts through Gamification," shifts the conversations of process to threshold concepts. Stinson explores how the WAW process of exposing threshold concepts of writing in the service of teaching declarative knowledge about writing led him to develop a procedural method to engage these threshold writing concepts: 
gamification. Jennifer deWinter explores the relationship between process and threshold concepts for students and instructors. In "Curricular Review in WAW: Involving Alumni, Students, and Faculty in Writing about Writing in Technical Fields," deWinter explores how a revised curriculum (moving to WAW) helped students gain a more complex, "nuanced" understanding of writing processes; in fact, the students she studied understood the value of writing as a discipline and the methods of research it involves by the end of her course. She also reveals how her curriculum redesign led to faculty in her writing program increasing their own knowledge of writing threshold concepts and research in writing studies in general.

\section{PART III: ENGAGEMENT}

WAW approaches to teaching writing not only invite students to develop their own writerly identities and develop metacognitive awareness of their processes, they also encourage student writers to deeply engage with themselves as writer-learners and engage with whatever content they are learning - in and out of the school setting. Of course we recognize that all writing teachers want their students to engage themselves as writers and engage the content. However, we have found that what most engages students as writers is the combination of the three key distinctions of a WAW approach: (1) using writing as content of the course, (2) viewing students as writers, and (3) instructors explicitly discovering new writing knowledge with their students. Each of these aspects of WAW invites deep engagement as writers: students are invited to give their perspectives on the content, are treated as writers above and beyond being students, and are co-learners with instructors. When students are asked their views and treated as writers and co-learners, especially in a classroom community, it leads to a powerful incentive for deep engagement.

Chapters in this section reveal how WAW approaches can and should move beyond typical FYC topics, which are often limited to academic genres and activities. Thus, the authors in these chapters explore wider WAW approaches with an eye on how these newer approaches reinforce the three principles of WAW while also broadening WAW approaches; thus, the authors in this section look at WAW courses from different angles, helping us to better understand how and why our students engage writing and themselves as writers.

Since this level of student engagement is foundational to any kind of transfer, we begin this section with a look at writing transfer. In "Transfer of Writing-Related Learning," Rebecca Nowacek argues that "we have 
not, as a field, sufficiently grappled with the question of what types of writing-related learning transfer." Nowacek's chapter also addresses key concepts and other writing knowledge and dispositions that most effectively lead to transferable or transformable writing practices.

We have found that WAW teachers do not aim to have students transfer writing skills but instead seek the transfer of deeper writing-related learning. The chapters that follow this theoretical opening to our engagement section position student writer engagement in the context of transfer. That is, the deeper writer-related learning that transfers, WAW teachers believe, is just the kind of learning that engages student writers since this learning is necessarily personal (identity-oriented) and intimately connected to their own processes. This conclusion is exemplified by "Writing about Writing Focus: A Roundtable" conducted by Kimberly Hoover with Elle Limesand, Maggie Hammond, and Max Wellman, three undergraduate students. Hoover's discussion of WAW highlights a significant outcome of WAW based on studies and program assessments: students' deep writing content knowledge, personal identification as writers, and strategies for addressing audiences.

In "Finding a Way into WAW: Extending Invitations across Disciplinary Lines," Matthew Bryan, Kevin Roozen, and Nichole Stack acknowledge that WAW requires a shift in our thinking and values. This chapter focuses on how WAW instructors articulate the value of WAW to other stakeholders, many of whom have little or no understanding of WAW principles and who have a range of disciplinary backgrounds, in order to productively engage a variety of stakeholders in conversations about writing instruction and literacy learning. In "Digital Composing in WAW: What Students Learn through Infographics," Christy I. Wenger turns the focus from instructors to students, articulating how WAW helps students become reflective consumers and producers of digital genres by increasing metaknowledge of audience and multimodality. This approach is useful for navigating the digital turn in FYW, but "trappings of expertise" can make WAW resistant to digital composing; thus, Wenger suggests that a digitally focused WAW course aim for mindfulness, not expertise. Also aiming for mindfulness is a student voice chapter, "Podcasting and Protocols: An Approach to Writing about Writing through Sound," written by Christian Smith with Gabrielle Frick and Patrick Siebel. Together, the voices of Smith, Frick, and Siebel suggest ways to improve WAW approaches using multimodal listening via think-aloud protocols. Smith contends that multimodal listening has made students more attentive to their own writing process by making that process "strange," which leads to a new WAW approach as "sonic composing." 
Closing out this section, "Play the Game but Refocus the Aim: Teaching WAW within Alternative Pedagogies," Katie Jo LaRiviere creates the concept of "double pedagogy," which she developed as her way into WAW within an argument-focused approach with a specified set of readings that must be taught. Her double pedagogy helps other instructors teaching within a restricted writing program to create WAW approach values within any program. LaRiviere's double pedagogy highlights what she sees as WAW's greatest virtue: its focus on actively and consistently promoting metacognitive thinking about writing and the self as writer.

\section{AFTERWARDS: NEXT STEPS}

We conclude with a reflective chapter considering implications for further development of writing about writing approaches based on the state of WAW teaching described throughout the book. What questions have these contributions answered about WAW approaches? What questions have they opened or created? In what ways have WAW approaches established a comfortable center of gravity that might continue to characterize a writing about writing ethos in college writing instruction, and in what ways do the descriptions here leave us, as researchers and teachers of WAW approaches, wanting more or feeling the need to strike out in new directions? What do the pieces in this book suggest is clearly possible, and what possibilities do they leave us only to imagine? 